\title{
Article \\ Chrysin-Loaded Microemulsion: Formulation Design, Evaluation and Antihyperalgesic Activity in Mice
}

Ízola Morais de Medeiros Ramalho ${ }^{1}$, Gabriela Suassuna Bezerra ${ }^{1}$, Elissa Arantes Ostrosky ${ }^{1}$, Márcio Ferrari ${ }^{1}$, Verônica da Silva Oliveira ${ }^{1}$, Alcides de Oliveira Wanderley Neto ${ }^{2}$, Jullyana de Souza Siqueira Quintans ${ }^{3}$, Fabiolla Rocha Santos Passos ${ }^{3}$, Luana Heimfarth ${ }^{3}$, Lucindo José Quintans-Júnior ${ }^{3}{ }^{\mathbb{D}}$, Bolí var Ponciano Goulart de Lima Damasceno ${ }^{4}$, Attilio Converti ${ }^{5, *}$ (i) and Ádley Antonini Neves de Lima ${ }^{1}$ (b)

check for updates

Citation: Ramalho, Í.M.d.M.; Bezerra, G.S.; Ostrosky, E.A.; Ferrari, M.; Oliveira, V.d.S.; Wanderley Neto, A.d.O.; Quintans, J.d.S.S.; Passos, F.R.S.; Heimfarth, L.; Quintans-Júnior, L.J.; et al. Chrysin-Loaded Microemulsion: Formulation Design, Evaluation and Antihyperalgesic Activity in Mice. Appl. Sci. 2022, 12, 477. https://doi.org/10.3390/ app12010477

Academic Editors: Artur Turek and Eva Martins

Received: 11 December 2021 Accepted: 22 December 2021 Published: 4 January 2022

Publisher's Note: MDPI stays neutral with regard to jurisdictional claims in published maps and institutional affiliations.

Copyright: (c) 2022 by the authors Licensee MDPI, Basel, Switzerland. This article is an open access article distributed under the terms and conditions of the Creative Commons Attribution (CC BY) license (https:// creativecommons.org/licenses/by/ $4.0 /$ )
1 Department of Pharmacy, Federal University of Rio Grande do Norte, Natal 59012-570, RN, Brazil; izola.ramalho.069@ufrn.edu.br (Í.M.d.M.R.); gabriela.suassuna.070@ufrn.edu.br (G.S.B.); elissa.arantes@ufrn.br (E.A.O.); marcio.ferrari@ufrn.br (M.F.); veronica.oliveira.082@ufrn.edu.br (V.d.S.O.); adley.lima@ufrn.br (Á.A.N.d.L.)

2 Institute of Chemistry, Federal University of Rio Grande do Norte, Natal 59012-570, RN, Brazil alcides.wanderley@ufrn.br

3 Laboratory of Neuroscience and Pharmacological Assays, Department of Physiology, Federal University of Sergipe, São Cristóvão 49100-000, SE, Brazil; jullyanas@academico.ufs.br (J.d.S.S.Q.); fabiollarsp@academico.ufs.br (F.R.S.P.); luahei@academico.ufs.br (L.H.); lucindo@academico.ufs.br (L.J.Q.-J.)

4 Center for Biological and Health Sciences, Department of Pharmacy, State University of Paraíba, Campina Grande 58429-600, PB, Brazil; bolivarpgld@servidor.uepb.edu.br

5 Department of Civil, Chemical and Environment Engineering, Pole of Chemical Engineering, University of Genoa, I-16145 Genoa, Italy

* Correspondence: converti@unige.it; Tel.: +39-010-3352593

\begin{abstract}
Chrysin is a bioactive flavonoid found in pollens, passion flowers, honey, royal jelly, and propolis, which is commonly used as an ingredient in natural food supplements and is primarily responsible for their pharmacological properties. A transparent chrysin-loaded microemulsion (CS-ME) prepared through a ternary phase diagram was evaluated for use as an antihyperalgesic formulation. It was formulated with $40 \%$ Labrasol $^{\circledR}$ (surfactant), $5 \%$ isopropyl myristate (oil phase) and $55 \%$ water (aqueous phase) and classified as an oil-in-water $(\mathrm{O} / \mathrm{W})$ microsized system $(74.4 \pm 15.8 \mathrm{~nm})$. Its negative Zeta potential $(-16.1 \pm 1.9 \mathrm{mV})$ was confirmed by polarized light microscopy and dynamic light scattering analysis. In vitro studies in Franz-type static diffusion cells showed that chrysin release from CS-ME followed zero-order kinetics. Oral administration of CS-ME in mice resulted in a statistically significantly reduction $(p<0.05)$ in carrageenan-induced mechanical hyperalgesia compared to the control group. Treatment with CS-ME also showed anti-inflammatory activity by significantly decreasing the TNF- $\alpha$ level $(p<0.01)$ and increasing that of IL-10 $(p<0.05)$ compared to the control group. These results suggest that the proposed microsystem is a promising vector for the release of chrysin, being able to improve its capacity to modulate inflammatory and nociceptive responses.
\end{abstract}

Keywords: microemulsion; drug delivery system; flavonoid; inflammation; pain; mechanical hyperalgesia

\section{Introduction}

Defined as dispersions between oil, surfactant, aqueous phase, and, frequently, cosurfactants, microemulsified systems were discovered in 1943 by Hoar and Schulman, who observed that an opaque emulsion stabilized by a surfactant became clear after the addition of a medium-chain length alcohol [1,2]. By changing the proportions of components, it is possible to prepare different microstructures that can be classified into three categories according to their physicochemical properties, namely oil-in-water, bicontinuous, and water-in-oil microemulsions [3]. Several advantages are provided by microemulsions 
over conventional formulations including ease of manufacturing, improved drug solubilization, good thermodynamic stability, protection against enzymatic hydrolysis, greater hydrophilic, hydrophobic and amphiphilic drug permeation, enhanced absorption due to surfactant-induced permeability, and increased bioavailability of hydrophobic compounds $[4,5]$. Consequently, microemulsions have been extensively studied as a promising system for the delivery of hydrophilic, lipophilic, or amphiphilic bioactive compounds in pharmaceutical, nutraceutical, and cosmetic applications [6].

Chrysin (5,7-dihydroxyflavone) consists of a natural flavonoid, found in honey, propolis [7], and in species of many plants such as Oroxylum indicum [8] and passion flower (Passiflora caerulea and Passiflora incarnata) [9,10]. It is regarded as "Generally Recognized as Safe" (GRAS) by the U.S. Food and Drug Administration (FDA) and commonly used in the U.S. market as a nutraceutical [11] and food supplement without side effects [12] as well as being one of the flavonoids responsible for the biological and functional properties of honey, royal jelly [13], and propolis [13,14].

Like other flavonoids, chrysin exhibits a broad-spectrum of pharmacological activities including as an antioxidant [8], antihemolytic [15], antitumor [16], hypolipidemic [7] and antihypertensive [17]. It is also reported to exert antinociceptive [18] and anti-inflammatory effects being able to inhibit several cytokines, nitric oxide, prostaglandin E, and cyclooxygenase2 [10]. Additionally, it is an aromatase (estrogen synthetase) inhibitor used as a dietary supplement $[19,20]$. Due to its abundance in plants, potential pharmacological and nutritional effects along with low systemic toxicity, chrysin is attracting considerable interest as an alternative to conventional therapeutic drugs. However, the use of chrysin as a drug is often hindered by its low water solubility $(0.005 \mathrm{mg} / \mathrm{mL})$, which greatly limits its bioavailability $[11,21,22]$. Hence, encapsulation within suitable delivery vehicles has been suggested as a method to overcome this drawback.

Inflammation is the response to tissue injury caused by endogenous and/or exogenous stimuli. It is characterized by biochemical, vascular, and cellular changes that lead to the activation of cellular and plasma components of the immune system, in order to remove the offending agent and restore tissue homeostasis [23]. Hyperalgesia is one of the main causes of the inflammatory process that occurs through the activation of cytokine cascade, resulting in the sensitization of nociceptive primary sensory neurons [24-26]. The drug therapies currently available to treat inflammatory diseases act through various mechanisms; however, if used for a long time, they are responsible for significant side effects. Therefore, other therapeutic options are being explored in the treatment of inflammatory pain [23,27]. In this context, as pro-inflammatory responses and the regulation of nociceptive sensitivity share common pathways, the property of flavonoids to inhibit pro-inflammatory stimuli may be successfully exploited to treat several acute and chronic inflammatory diseases as well as nociceptive sensitivity [18]. Indeed, since such compounds including chrysin can act as potent inhibitors of oxidative stress, membrane stabilizers, inhibitors of inflammatory cytokines, and stimulators of anti-inflammatory cytokines, they are promising pharmacological tools for the course of inflammatory and neurogenic pain $[9,28]$.

Regarding drug delivery systems, the aims of this study are (a) the development of a new chrysin-loaded microemulsion system (CS-ME); (b) its characterization in terms of physicochemical parameters; (c) the kinetic study of chrysin release from CS-ME; and (d) the assessment of chrysin and CS-ME antihyperalgesic activity in mice.

\section{Materials and Methods}

Chrysin was acquired from Sigma-Aldrich (São Paulo, Brazil), isopropyl myristate (IPM) from Farmos (Rio de Janeiro, Brazil), caprylocaproyl polyoxyl-8 glycerides (LAS) from Brasquim (São Paulo, Brazil), and carrageenan from Sigma (St. Louis, MO, USA).

\subsection{Construction of Ternary Phase Diagrams}

To identify the ratios of components corresponding to the area of microemulsion existence, ternary phase diagrams were constructed using the water titration method at 
$25^{\circ} \mathrm{C}$ [29]. IPM was used as the oil phase, LAS as the surfactants, and reverse osmosis water as the aqueous phase. Oil phase and surfactant blends were thoroughly mixed in different weight ratios, namely 1:9, 2:8, 3:7, 4:6, 5:5, 6:4, 7:3, 8:2, and 9:1 (\%w/w). Each mixture was gradually titrated dropwise with reverse osmosis water followed by a sonication cycle for 1 min using a $750 \mathrm{~W}, 20 \mathrm{kHz}$, Vibracell 75041 ultrasound sonicator (Bioblock Scientific, Illkirch, France) equipped with a 13-mm horn (CV33) at 40\% amplitude. After bubbles had been removed by an ultrasonic cleaner (Unique, Indaiutaba, Brazil) and the mixtures equilibrated for $2 \mathrm{~min}$, visual observation allowed the resulting dispersions to be classified as microemulsions, crude emulsions, or separate phases. The results were analyzed using Origin Pro 8.0 software. Based on this diagram, appropriate ratios of oil, surfactant, and water were selected for the preparation of CS-ME.

\subsection{Preparation of Chrysin-Loaded Microemulsion}

CS-MEs were prepared in the selected component ratios. Due to the lipophilic nature of chrysin, it was added to oil and surfactant blends. After the addition of water to the formulation, three 1-min sonication cycles were performed using the same ultrasound sonicator described above, followed by bubble removal using the aforementioned ultrasonic cleaner.

\subsection{Characterization of Chrysin-Loaded Microemulsion}

\subsubsection{Macroscopic Appearance}

Aspects such as homogeneity, color, transition from a clear to cloudy system, and formation of precipitates or phase separation were assessed by visual observation $24 \mathrm{~h}$ after the preparation of the microemulsion.

\subsubsection{Determination of Chrysin Content and Encapsulation Efficiency}

After dissolution of CS-ME in ethanol (1:250 $v / v)$, chrysin concentration was determined by absorbance measurements at $269 \mathrm{~nm}$ using a UV/Vis spectrophotometer, model Evolution $60 \mathrm{~S}$ (Thermo Scientific, Madison, WI, USA), and total chrysin concentration $\left(C_{t}\right)$ in CS-ME was expressed in $\mathrm{mg}$ of chrysin/ $\mathrm{mL}$ of microemulsion [30]. To measure the encapsulation efficiency (EE), $1.0 \mathrm{~g}$ of CS-ME was centrifuged at $15,000 \times \mathrm{g}$ for $30 \mathrm{~min}$ to remove undissolved chrysin. A known volume of supernatant was 1:250 $(v / v)$ diluted with ethanol, and the chrysin concentration in the supernatant was assumed to be the concentration of the encapsulated $\operatorname{drug}\left(C_{e}\right)$. EE was calculated as the ratio of $C_{e}$ to $C_{t}$ and expressed as a percentage according to $\mathrm{Li}$ et al. [31]:

$$
E E(\%)=\left(C_{e} / C_{t}\right) \times 100,
$$

\subsubsection{Physicochemical Parameters}

Measurements of the physicochemical parameters of the prepared CS-ME were carried out $24 \mathrm{~h}$ after preparation. Mean values of conductivity, $\mathrm{pH}$, and refractive index were determined using a conductivity meter (Logen, Brazil), a pH meter (model HI 221, Hanna instruments, São Paulo, Brazil), and an Abbe refractometer (Analytik Jena AG, Jena, Germany), respectively. Surface tension was characterized using a SensaDyne tensiometer (model QC-6000, Chem-Dyne Research Corp., Milwaukee, WI, USA) by means of the maximum pressure bubble method with nitrogen as the gas phase. The tensiometer was connected to a computer and controlled by the SensaDyne Tensiometer software, version 1.21. All physicochemical parameters were measured at room temperature $\left(25 \pm 1^{\circ} \mathrm{C}\right)$ in triplicate.

\subsubsection{Polarized Light Microscopy}

CS-ME was characterized as an isotropic material using a cross-polarized light microscope (BX-50, Olympus Start, Tokyo, Japan). For this purpose, before microscopic examination, a sample aliquot was added to a glass slide and covered with a cover slip. 


\subsubsection{Droplet Size, Zeta Potential and Polydispersity Index}

Mean droplet size, Zeta potential, and polydispersity index (PDI) of CS-ME were determined by dynamic light scattering (DLS) with a Zetasizer Nano ZS90 (Malvern Instruments, Orsay, France). Samples for Zeta potential measurements were diluted in $1.0 \mathrm{mM} \mathrm{NaCl}$. All measurements were made in triplicate, at room temperature, with a 633-nm standard laser using a 90 degree scattering angle.

\subsubsection{Thermodynamic Stability}

To evaluate the thermodynamic stability of CS-ME, it was submitted to tests of centrifuge stress and freeze-thaw cycle stress as well as to heating and cooling cycles. Effective NEs should in fact persist as single phase isotropic transparent systems, showing no cracking, no phase separation, and no creaming after tests [5,32]. For the centrifuge stress test, NE formulation was centrifuged at $15,000 \times g$ for $30 \mathrm{~min}$, and the appearance of turbidity or phase separation was checked. For the freeze-thaw cycle stress test, NE formulation was submitted to three cycles of freezing at $-20{ }^{\circ} \mathrm{C}$ in a deep freeze and subsequent thawing at room temperature after $24 \mathrm{~h}$. For heating and cooling cycles, NE formulation was subjected to three cycles of $24 \mathrm{~h}$-heating at $37^{\circ} \mathrm{C}$ and subsequent natural cooling to room temperature.

\subsection{In Vitro Drug Release from Chrysin-Loaded Microemulsion}

The in vitro drug release from CS-ME was studied in a Franz diffusion cell. The effective diffusion surface area and receptor compartment mean volume were $0.785 \mathrm{~cm}^{2}$ and $12 \mathrm{~mL}$, respectively. Synthetic cellulose acetate membranes with $0.45-\mu \mathrm{m}$ pore diameter (Millipore, Barueri, Brazil) were washed in phosphate buffer, $\mathrm{pH} 7.4$, for $2 \mathrm{~h}$ before being mounted between the compartments. A 1:1 $(v / v)$ ethanol/water solution was used as the receptor fluid to assure sink conditions, considering that chrysin concentration in the medium represented $\leq 10 \%$ of the saturation solubility. This medium was constantly stirred and maintained at $37 \pm 0.5^{\circ} \mathrm{C}$ to simulate body temperature on the membrane surface. After placement of cellulose acetate membranes in the Franz diffusion cell, $0.3 \mathrm{~mL}$ of CS-ME formulation was placed in the donor chamber and sealed with paraffin wax to minimize environmental disturbances. Successful collector conditions were ensured by replacing the receptor solution after withdrawing it from the receptor compartment at predefined times and magnetically stirring at a rotational speed of $300 \mathrm{rpm}$. One $\mathrm{mL}$ of the receptor solution was withdrawn after $0.25,0.5,1,2,4,6,8,10$, and $12 \mathrm{~h}$, and then replaced. The amount of drug passed through the membrane was measured spectrophotometrically as described previously. All experiments were carried out in triplicate, and kinetic parameters of release were compared by one-way ANOVA at $95 \%$ confidence interval.

The cumulative amount of chrysin released $\left(R_{t}\right)$ was divided by the surface exposed area and expressed in $\mu \mathrm{g} / \mathrm{cm}^{2}$, and data were plotted as a function of time $(t)$. The percentage of drug release $(P)$ was determined by the equation:

$$
P(\%)=\left(R_{t} / L\right) \times 100,
$$

where $L$ the initial chrysin content of CS-ME.

\section{Kinetic Modeling of Drug Release from Chrysin-Loaded Microemulsion}

The experimental data of chrysin release were fitted to different kinetic models including zero-order ( $R_{t}$ versus time), first-order ( $\ln R_{t}$ versus time), and Higuchi ( $R_{t}$ versus square root of time) models [33]. The mathematical model ensuring the highest coefficient of linear correlation $\left(\mathrm{r}^{2}\right)$ was selected to describe the release profile. The flux of chrysin across the synthetic membranes $(J)$ was calculated by the linear regression of steady-state data corresponding to the linear portion of the slope [32,34]. The latency time was assumed to correspond to the point of intersection on the time axis of the steady-state line. The 
release coefficient $\left(K_{r}\right)$ was calculated as the ratio of the flux of chrysin at steady state $\left(J_{s s}\right)$ to the initial drug concentration $\left(C_{o}\right)$ in the vehicle according to the equation

$$
K_{r}=J_{s s} / C_{o},
$$

\subsection{Anti-Hyperalgesic Activity of Chrysin-Loaded Microemulsion}

\subsubsection{Animals}

Experiments were performed with adult male albino Swiss mice (25-30 g) obtained from the Animal Facilities of the Federal University of Sergipe (UFS, Aracajú, Brazil). Mice were randomly maintained in appropriate polypropylene cages at constant room temperature $\left(21 \pm 2{ }^{\circ} \mathrm{C}\right)$ under a 12-h light/dark cycle (lights on 6:00 a.m. to 6:00 p.m.) with access to water and food at will. The experimental groups of mice $(n=8)$ were acclimatized for at least $2 \mathrm{~h}$ before and used only once. Tests were performed during the light phase of the cycle. The experimental protocols were approved by the Animal Care and Use Committee at the UFS (CEPA/UFS \# 69/16). The minimum number of animals required was used to minimize animal suffering. Behavioral protocols were performed blind.

\subsubsection{Carrageenan-Induced Inflammation}

Mice were divided into five groups, namely the sham group (no inflammation induction and untreated); chrysin group (treated with $25 \mathrm{mg} / \mathrm{kg}$ of chrysin); CS-ME group (treated with microemulsion containing chrysin at the same dosage); and the negative control groups, denominated Control (treated with saline solution) and Blank-ME (treated with microemulsion without chrysin). In all groups except in the sham group, acute inflammation was induced in the right hind paw by subcutaneous injection of $50 \mu \mathrm{L}$ of $1 \%$ carrageenan solution in saline, $30 \mathrm{~min}$ after oral administration by gavage of each treatment.

\section{Carrageenan-Induced Mechanical Hyperalgesia}

Mechanical hyperalgesia was assessed using a digital analgesimeter (Insight, Ribeirão Preto, Brazil). Constantly increasing force was applied to the right hind paw until the mice withdrew their hind paws or "flinched". Behind the paw withdrawal, the force intensity (g) was recorded automatically. Four measurements were taken in each animal (with an interval of $5 \mathrm{~min}$ ) to obtain an average value expressed in grams. Measures were made before carrageenan injection to characterize the baseline response as well as 1,2,3, and $4 \mathrm{~h}$ after induction.

\section{Cytokines Assays}

After $4 \mathrm{~h}$ of carrageenan injection, the same animals were euthanized, and the right hind paw skin was removed and stored at $-80^{\circ} \mathrm{C}$. The skin tissues were homogenized in $200 \mu \mathrm{L}$ of phosphate-buffered saline (PBS, $\mathrm{pH} 7.4$ ) containing $0.3 \%$ EDTA, $0.5 \%$ Nonidet $\mathrm{P}-40$, and protease inhibitors. Samples were centrifuged at $8000 \mathrm{rpm}$ for $10 \mathrm{~min}$ at $4{ }^{\circ} \mathrm{C}$, and the supernatant was diluted for the protein dosage. Protein content was determined using the Bradford method. TNF- $\alpha$ and IL-10 levels were determined by the enzyme-linked immunosorbent assay (ELISA). For this purpose, the ELISA kit of eBioscience (San Diego, CA, USA) was used according to the protocol instructions, and colorimetric measurements at $450 \mathrm{~nm}$ were made in a microplate reader (ASYS). The concentration was obtained by interpolation from a standard curve. All results were expressed as picograms (pg) of cytokine per milligram $(\mathrm{mg})$ of total protein.

\subsection{Statistical Analysis}

The statistical analyses were performed using GraphPad Prism 6.0 (GraphPad Prism Software Inc., San Diego, CA, USA) software. Data were assessed by one-way analysis of variance (ANOVA) followed by Tukey's test for antinociceptive and anti-inflammatory activities. Differences were considered significant when $p<0.05$. 


\section{Results and Discussion}

\subsection{Ternary Phase Diagram and Preparation of Chrysin-Loaded Microemulsion}

To obtain the best proportions of components to form microemulsions (NEs), ternary phase diagrams were constructed for the oil, surfactant, and aqueous phases, which are illustrated in Figure 1. Several types of systems were formed and classified as NEs, crude emulsions, or separate phases. Based on these results, the 5\% (w/w) oil, 40\% (w/w) surfactant, and $55 \%(w / w)$ aqueous phase composition was selected from the NE region, because it ensured the formation of the most stable system. It has been suggested that the drug should be incorporated into the formulation before it is fully ready to ensure maximum encapsulation efficiency; therefore, to obtain CS-ME, chrysin was initially incorporated into the blend of oil and surfactant phase during the formation of the NE.

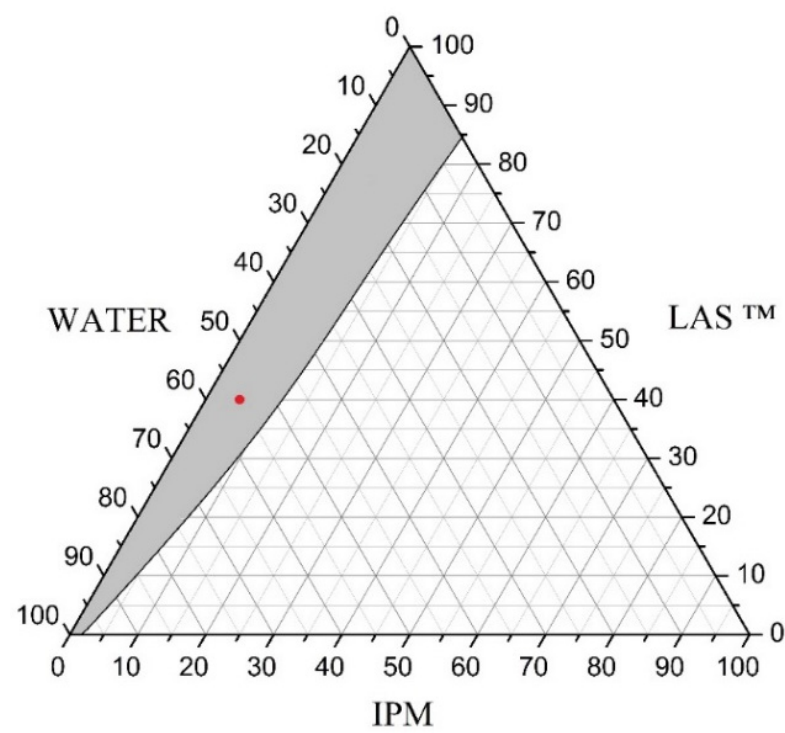

Figure 1. Ternary phase diagrams formed by a mixture of isopropyl myristate (IPM) as the oil phase, caprylocaproyl polyoxyl-8 glycerides (LAS) as the surfactant, and water as the aqueous phase. The gray area represents the microemulsion system region, and the red dot within this area the selected formulation.

\subsection{Characterization of Chrysin-Loaded Microemulsion}

3.2.1. Macroscopic Appearance, Chrysin Content, and Microemulsion Encapsulation Efficiency

The CS-ME obtained appeared as an optically clear, homogeneous, transparent, and slightly yellow colored system, without any precipitate formation or phase separation, whose chrysin content and mean encapsulation efficiency $(E E)$ were $1 \mathrm{mg} / \mathrm{mL}$ and 97.7\%, respectively. Compared to chrysin solubility in water $(0.005 \mathrm{mg} / \mathrm{mL})$, the microemulsion allowed for an approximately 200-fold increase in concentration in the aqueous dispersion. Furthermore, since $E E$ values $>80 \%$ are considered satisfactory for a NE system, the incorporation of chrysin into CS-ME prior to its complete formation has proven to be a very efficient method of NE preparation.

\subsubsection{Physicochemical Parameters and Polarized Light Microscopy}

Physicochemical parameters such as electrical conductivity, $\mathrm{pH}$, refractive index, and surface tension were determined to characterize CS-ME. Since the conductivity of oilin-water $(\mathrm{O} / \mathrm{W}) \mathrm{NEs}$, having water as a continuous phase, is much higher than that of water-in-oil (W/O) NEs, having oil as a continuous phase [35], the very high conductivity of CS-ME $(24.66 \pm 0.25 \mu \mathrm{S} / \mathrm{cm})$ suggests that it was an $\mathrm{O} / \mathrm{W}$ NE system. The mean $\mathrm{pH}$ value $(4.48 \pm 0.10)$ was within the biologically accepted range for oral administration $(2-10)$, and the refractive index $(1.3894 \pm 0.0001)$ showed no statistically significant dif- 
ference after several repeated measurements. Moreover, the low surface tension value $(40.53 \pm 1.8$ dynes $/ \mathrm{cm})$, which can help increase chrysin bioavailability by improving its permeation through the gastrointestinal hydration layer [4], could have been mainly due to the high concentration of non-ionic surfactants used to prepare the microemulsion, which are well known to reduce this physicochemical property at the oil-water interface [36,37]. Finally, when CS-ME was examined with a polarized light microscope, it appeared as a completely dark field (data not shown). These results, together with those of the refractive index, revealed the optically isotropic nature of CS-ME, which is typical of NE systems [34].

\subsubsection{Droplet Size and Zeta Potential}

Dynamic light scattering analyses performed on drug-free-ME (blank) and CS-ME to determine the apparent average size of droplets, polydispersity index (PDI), and Zeta potential. Microemulsions were monodisperse, the mean value of drug-free-ME diameter being only $61.1 \pm 10.3 \mathrm{~nm}$ with PDI of $0.378 \pm 0.1$ and that of the drug-loaded one no larger than $74.4 \pm 15.8 \mathrm{~nm}$ with PDI of $0.313 \pm 0.09$. The Zeta potentials of Blank-ME and CS-ME were $-10.0 \pm 2.1 \mathrm{mV}$ and $-16.1 \pm 1.9 \mathrm{mV}$, respectively, which means that chrysin addition to the proposed system significantly increased its electrical field. This effect also suggests that chrysin interacted with the surfactant monolayer by changing its potential, therefore it was probably not only confined into the aqueous droplets but also present at the oil-water interface [34].

\subsubsection{Thermodynamic Stability}

Based on its appearance and results of thermodynamic stability tests (i.e., centrifuge stress, freeze-thaw cycle stress, and heating and cooling cycles), CS-ME behaved as a homogeneous, transparent, single-phase formulation without any precipitation, creaming, aggregation, or separation into two phases for a time period of three months. Such good physical stability could be attributed both to the very low interfacial tension between the water and oil phases of the formulation and the small droplet size [38].

\subsection{Kinetics of In Vitro Drug Release from Chrysin-Loaded Microemulsion}

The in vitro release profile of colloidal drug delivery systems is one of the most important physicochemical characteristics for predicting their in vivo performance, for correlating it to the carrier microstructure, and for designing formulations with the desired properties [39]. With these goals in mind, in vitro drug release tests were carried out to verify the vehicle ability to release the drug and understand the rate at which this phenomenon occurs. As shown in Figure 2, chrysin release from CS-ME through a synthetic cellulose acetate membrane was continuous and slow, grew up to $12 \mathrm{~h}$ without the burst effect, and then achieved a plateau, corresponding to the total percentage of chrysin released from CS-ME of $31.21 \%$. Such a release profile was probably due to the drug confinement in droplets coated by a surfactant monolayer and/or to CS-ME thermodynamic activity or partitional capacity between the oil and aqueous phases [40].

A linear regression analysis on the experimental data of the cumulative amount of chrysin released $\left(R_{t}, \mu \mathrm{g} / \mathrm{cm}^{2}\right)$ was conducted to identify the kinetic model that best described drug release. For this purpose, three different models, namely zero-order $\left(R_{t}\right.$ versus time), first-order (ln $R_{t}$ versus time), and Higuchi ( $R_{t}$ versus square root of time) models were tested, which provided correlation coefficients $\left(\mathrm{r}^{2}\right)$ of 0.9907, 0.9249, and 0.9503, respectively. These results, which confirm zero-order kinetics for chrysin release from CSME [34], are typical of drug delivery systems suitable for prolonged pharmacological action and resistant to disaggregation, with the active substance being released slowly and regardless of the initial drug concentration [41]. The most important examples of such systems are those employed for the delivery of antibiotics, antidepressants, and medicines for the maintenance of heart and blood pressure and for pain control [42].

The release coefficient $\left(K_{r}\right)$, calculated from flux and initial drug concentration using Equation (3), was $11.2 \mu \mathrm{g} / \mathrm{cm}^{2} \mathrm{~h}$, and the lag time for chrysin release to achieve a constant 
rate was only $9.8 \mathrm{~min}$. Although the in vitro release studies through artificial membranes only provide an indication of the behavior of drug-loaded microemulsions in terms of vehicle ability to deliver the drug, they are usually considered as a satisfactory and unique tool for highlighting the role of NE components and microstructure in drug release. Based on these considerations, the values of percent release, lag time, and $K_{r}$ obtained in this study for CS-ME can be considered promising for further studies.

A

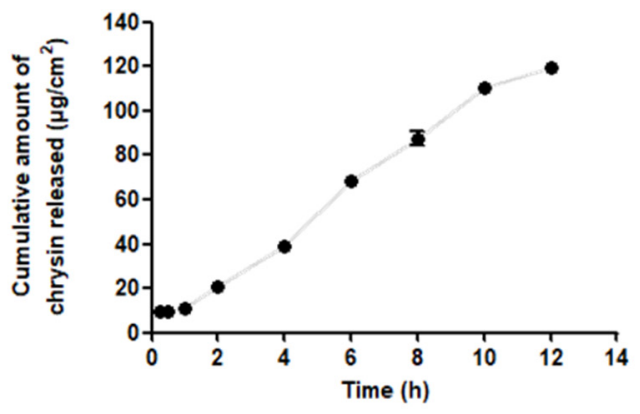

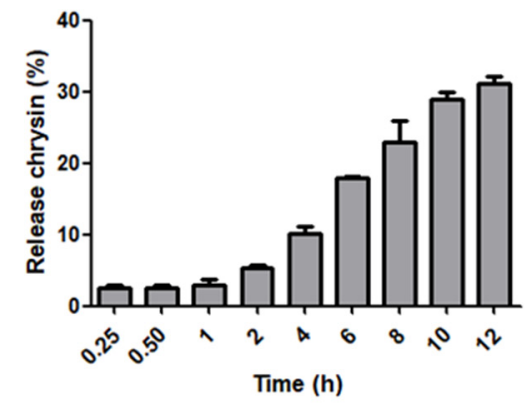

C
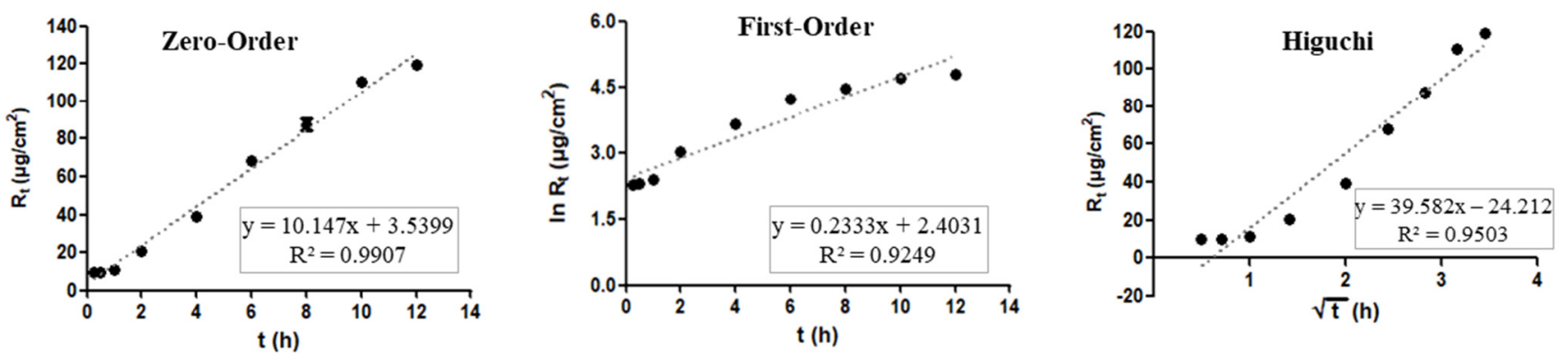

Figure 2. (A) In vitro profile of cumulative amount of chrysin released from microemulsion through a synthetic cellulose acetate membrane. (B) Percentage of release $(\%)$ of chrysin at each time $(n=3)$. (C) Fitted plots of drug release profiles by using the zero order, first order, and Higuchi models, where $R_{t}$ represents the cumulative amount of chrysin released.

\subsection{Antinociceptive Activity of Chrysin-Loaded Microemulsion}

The hyperalgesia induced by intraplantar injection of carrageenan (CG) is widely used to test the efficacy of new anti-inflammatory and antihyperalgesic compounds in preclinical models [43]. In particular, edema (swelling), hypersensitivity to a noxious stimulus (hyperalgesia), or sensitivity to a non-noxious stimulus (allodynia) can be used to assess inflammation in an animal model after CG administration. CG administration is in fact well known to induce the development of cardinal signs of inflammation as a consequence of the action of pro-inflammatory agents (mainly pro-inflammatory cytokines such as IL-1 $\beta$, IL-6, and TNF $\alpha$ ) as well as complement and reactive oxygen and nitrogen species. Inflammation manifests itself in a biphasic cutaneous reaction in the injected area, which consists of a first release of serotonin and histamine (up to $2 \mathrm{~h}$ later), followed by the release of bradykinin (3-6 h) occurring through the production of cytokines and prostaglandins by both local cells and infiltered neutrophils [44-46]. The release of prostanoids and sympathomimetic amines stimulates peripheral $\mathrm{A} \delta$ and $C$ fiber sensory nerve terminals, hence contributing to the consequent peripheral and central hyperalgesia [44].

Oral administration of CS-ME and chrysin in a $25 \mathrm{mg} / \mathrm{kg}$ dose resulted in a statistically significant reduction $(p<0.05)$ in CG-induced mechanical hyperalgesia compared to both the control and sham groups up to $4 \mathrm{~h}$ (Figure 3), while the Blank-ME group showed significant difference from the control group only $1 \mathrm{~h}$ after CG induction. 
A

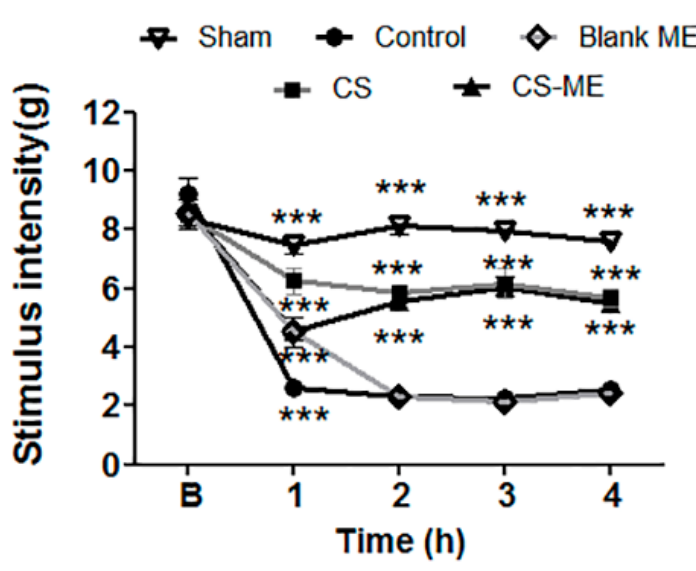

B

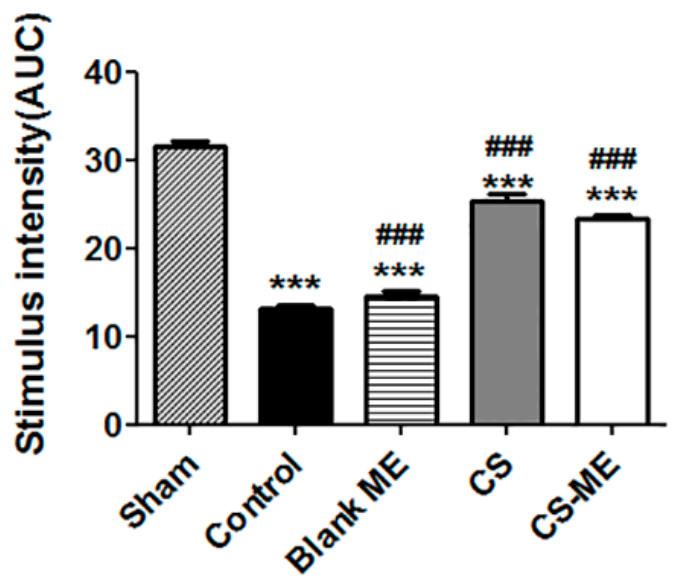

Figure 3. (A) Effects of chrysin (CS), chrysin-loaded microemulsion (CS-ME) $(25 \mathrm{mg} / \mathrm{kg}$ ) and blank$\mathrm{ME}$ on the carrageenan-induced mechanical hyperalgesia. All treatments were carried out $30 \mathrm{~min}$ before carrageenan injection. The intensity of the force $(\mathrm{g})$ needed for the mice to withdraw their hind paws or to "flinch" was determined using a digital analgesimeter $1 \mathrm{~h}$ before (baseline) as well as 1, 2, 3 , and $4 \mathrm{~h}$ after carrageenan injection. (B) Area under the curve (AUC) for antihyperalgesic effect of CS and CS-ME from 0 to $4 \mathrm{~h}$. Results are expressed as means \pm standard error of the mean $(\mathrm{n}=8)$ : *** $p<0.001$ vs. the control group; \#\#\# $p<0.01$ vs. the sham group; (one-way ANOVA followed by Tukey's test).

Previous reports have demonstrated that chrysin inhibits COX-2 expression in both in vitro and in silico inflammation models $[18,47]$. The results of this study indicate that chrysin may be involved in other paths of the inflammatory cascade, thereby reducing mechanical hyperalgesia. However, after $1 \mathrm{~h}$ of CG induction, Blank-ME treated animals also showed a significant $(p<0.05)$ antinociceptive effect, which suggests that at least one of the NE constituents may have interacted with some mediators involved in the inflammatory process.

Additionally, it has recently been demonstrated that chrysin is able to effectively relieve oxidative insults and apoptosis in primary rat mesencephalic cultures and to exert a protective effect against brain damage induced by chronic cerebral hypoperfusion in rodents [48]. These neuroprotective and anti-inflammatory effects appear to be associated with the antioxidant profile of chrysin, along with its ability to reduce the levels of inflammatory mediators such as NF-kB p65 unit, TNF- $\alpha$, IL-1 $\beta$, and IL-6 [49].

Since the observed antihyperalgesic effects of CS-ME and chrysin on the tested CGinduced inflammatory pain model may be associated with the regulation of inflammatory cytokine expression, levels of TNF- $\alpha$ and IL-10 were measured to help understand the mechanism of chrysin activity. The levels of pro-inflammatory (TNF- $\alpha$ ) and anti-inflammatory (IL-10) cytokines in the control group were significantly $(p<0.05)$ different from those in 
the sham group (Figure 4). All treatments significantly reduced $(p<0.05)$ the TNF- $\alpha$ level in the mouse paw compared with the control group after $4 \mathrm{~h}$ of CG injection. It is important to remember that TNF- $\alpha$ is one of the key cytokines in the control of inflammation, being responsible for important effects of the repair process, and is the first cytokine released after an inflammatory stimulus such as carrageenan injection. It leads to an increase in TNFR1and TNFR2-mediated COX and PGE2 expression and induces neutrophil migration to the injury site by indirect mechanisms (e.g., induction of chemotactic factors release through the resident macrophages and stimulation of leukotriene pathway) [50,51]. The fact that a reduction in TNF- $\alpha$ level was observed not only by administering chrysin and CS-ME, but interestingly, even with Blank-ME, corroborates our hypothesis that the microemulsion itself may have interacted with some modulators of inflammatory responses [52].
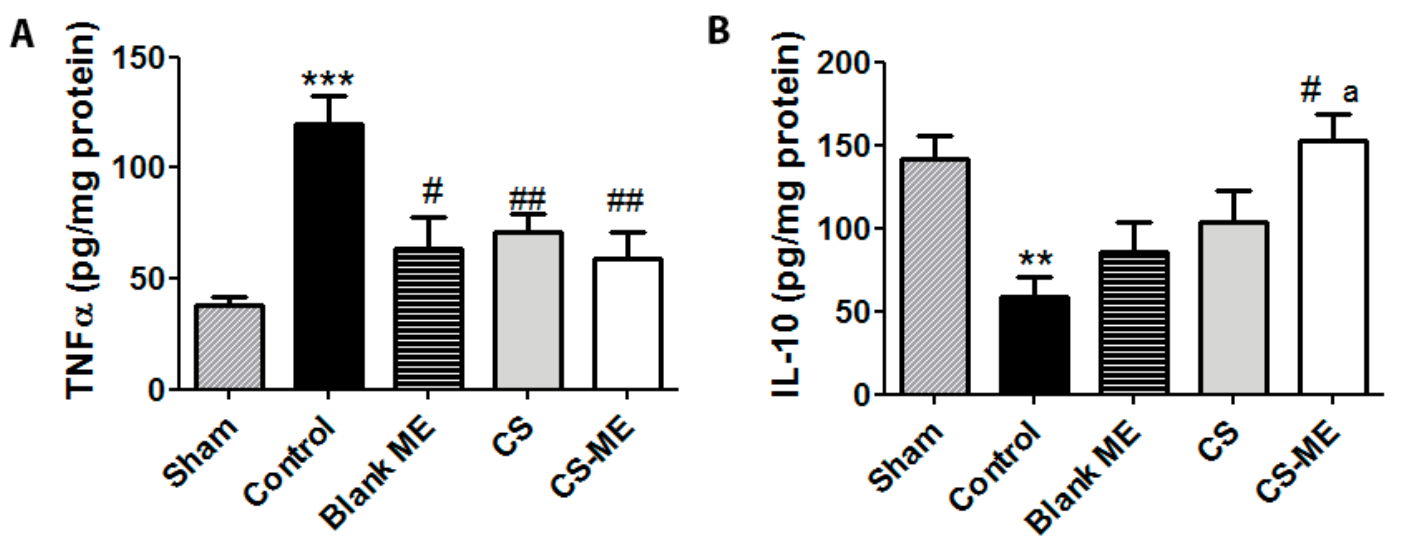

Figure 4. Effects of chrysin (CS), chrysin-loaded microemulsion (CS-ME) (25 mg/kg), and blank-ME on the expression of inflammatory cytokines, TNF- $\alpha$ (A) and IL-10 (B). Results are expressed as means \pm standard error of the mean $(\mathrm{n}=8)$ : ${ }^{* *} p<0.01 \mathrm{vs}$. the sham group; ${ }^{* * *} p<0.001 \mathrm{vs}$. the sham group; \# $p<0.05$ vs. the control group; \#\# $p<0.01$ vs. the control group; "a" $p<0.05$ vs. blank-ME (one-way ANOVA followed by Tukey's test).

Meanwhile, CS-ME significantly $(p<0.05)$ enhanced IL-10 levels when compared to the control group, while neither chrysin alone, nor Blank-ME had significant effects (Figure 4). It is worth mentioning that IL-10 is one of the most intriguing anti-inflammatory cytokines because it inhibits not only macrophages and monocytes, but also the production of pro-inflammatory cytokines such as TNF- $\alpha$ [50,53]. CS-ME was able to improve chrysin anti-inflammatory activity, and IL-10 appeared to play a pivotal role. The upregulation of IL-10 is an additional factor that may have contributed to the antihyperalgesic effect of chrysin shown in the CG-induced inflammatory pain model. However, further experiments are needed to confirm the mechanism of chrysin action in the treatment of hyperalgesia as well as the interaction of the microemulsion with inflammatory response pathways.

\section{Conclusions}

The dataset obtained in this study demonstrated that chrysin-loaded microemulsions (CS-ME) were actually developed and that the formulation was able to incorporate the poorly water-soluble flavonoid into the oil droplets, forming a stable oil-in-water-type microemulsion. Moreover, the release studies suggested zero-order kinetics. These features highlight the potential of this novel system mainly as a microcarrier for the prolonged and controlled delivery of hydrophobic drugs. Furthermore, CS-ME was shown to improve the antihyperalgesic and anti-inflammatory activities of chrysin, which appeared to be mediated, at least in part, by inhibition of TNF- $\alpha$ expression and upregulation of IL-10. These findings suggest the therapeutic potential of chrysin against inflammatory pain, however, further studies are needed regarding its effect and analgesic application. CS-ME appears to be a promising microscale carrier to treat painful inflammatory conditions, among the advantages of which may be non-invasiveness, absence of pain, ease of application due to 
oral administration, controlled drug release, and increased adherence from the patient to the treatment.

Author Contributions: Conceptualization, Í.M.d.M.R. and Á.A.N.d.L.; Methodology, Í.M.d.M.R., G.S.B., E.A.O., M.F., A.d.O.W.N., A.C.,F.R.S.P. and L.H.; Validation, J.d.S.S.Q., F.R.S.P., L.H., L.J.Q.-J. and B.P.G.d.L.D.; Formal analysis, A.d.O.W.N., J.d.S.S.Q., F.R.S.P.; L.H., A.C. and L.J.Q.-J.; Investigation, I.M.d.M.R., A.d.O.W.N. and L.J.Q.-J.; Resources, Á.A.N.d.L.; Data curation, Í.M.d.M.R. and J.d.S.S.Q.; Writing—original draft preparation, I.M.d.M.R., G.S.B. and V.d.S.O.; Writing-review and editing, V.d.S.O., A.C. and Á.A.N.d.L.; Supervision, Á.A.N.d.L.; Project administration, Á.A.N.d.L.; Funding acquisition, Á.A.N.d.L. All authors have read and agreed to the published version of the manuscript.

Funding: This research was funded in part by the Coordenação de Aperfeiçoamento de Pessoal de Nível Superior-Brasil (CAPES)-Finance Code 001.

Institutional Review Board Statement: The study was conducted according to the guidelines of the Declaration of Helsinki and approved by the Animal Care and Use Committee at the Federal University of Sergipe (UFS) (protocol CEPA/UFS \# 69/16).

Informed Consent Statement: Not applicable.

Data Availability Statement: The data presented in this study are available on request from the corresponding author. The data are not publicly available due to privacy.

Acknowledgments: The authors would like to acknowledge the financial support from CAPES, CNPq, and FAPITEC/SE.

Conflicts of Interest: The authors declare no conflict of interest.

\section{References}

1. Tartaro, G.; Mateos, H.; Schirone, D.; Angelico, R.; Palazzo, G. Microemulsion microstructure(s): A tutorial review. Nanomaterials 2020, 10, 1657. [CrossRef] [PubMed]

2. Rakshit, A.K.; Naskar, B.; Moulik, S.P. Commemorating 75 years of microemulsion. Curr. Sci. 2019, 116, 898-912. [CrossRef]

3. Mehta, D.; Rathod, H. Microemulsions: A Potential Novel Drug Delivery System. Acta Sci. Int. J. Pharm. Sci. $2015,1,48$.

4. Kaur, G.; Mehta, S.K. Developments of Polysorbate (Tween) based microemulsions: Preclinical drug delivery, toxicity and antimicrobial applications. Int. J. Pharm. 2017, 529, 134-160. [CrossRef]

5. Mouri, A.; Legrand, P.; El Ghzaoui, A.; Dorandeu, C.; Maurel, J.C.; Devoisselle, J.M. Formulation, physicochemical characterization and stability study of lithium-loaded microemulsion system. Int. J. Pharm. 2016, 502, 117-124. [CrossRef]

6. Mouri, A.; Diat, O.; Lerner, D.A.; El Ghzaoui, A.; Ajovalasit, A.; Dorandeu, C.; Maurel, J.C.; Devoisselle, J.M.; Legrand, P. Water solubilization capacity of pharmaceutical microemulsions based on Peceol ${ }^{\circledR}$, lecithin and ethanol. Int. J. Pharm. 2014, 475, 324-334. [CrossRef]

7. Zarzecki, M.S.; Araujo, S.M.; Bortolotto, V.C.; de Paula, M.T.; Jesse, C.R.; Prigol, M. Hypolipidemic action of chrysin on Triton WR-1339-induced hyperlipidemia in female C57BL/ 6 mice. Toxicol. Reports 2014, 1, 200-208. [CrossRef]

8. Pushpavalli, G.; Kalaiarasi, P.; Veeramani, C.; Pugalendi, K.V. Effect of chrysin on hepatoprotective and antioxidant status in d-galactosamine-induced hepatitis in rats. Eur. J. Pharmacol. 2010, 631, 36-41. [CrossRef]

9. Diniz, T.C.; Silva, J.C.; De Lima-Saraiva, S.R.G.; Ribeiro, F.P.R.D.A.; Pacheco, A.G.M.; De Freitas, R.M.; Quintans-Júnior, L.J.; Quintans, J.D.S.S.; Mendes, R.L.; Almeida, J.R.G.D.S. The role of flavonoids on oxidative stress in epilepsy. Oxid. Med. Cell. Longev. 2015, 2015, 171756. [CrossRef] [PubMed]

10. Bae, Y.; Lee, S.; Kim, S.H. Chrysin suppresses mast cell-mediated allergic inflammation: Involvement of calcium, caspase-1 and nuclear factor-kB. Toxicol. Appl. Pharmacol. 2011, 254, 56-64. [CrossRef] [PubMed]

11. Walle, T.; Otake, Y.; Brubaker, J.A.; Walle, U.K.; Halushka, P.V. Disposition and metabolism of the flavonoid chrysin in normal volunteers. Br. J. Clin. Pharmacol. 2001, 51, 143-146. [CrossRef]

12. Timcheh-Hariri, A.; Balali-Mood, M.; Aryan, E.; Sadeghi, M.; Riahi-Zanjani, B. Toxic hepatitis in a group of 20 male body-builders taking dietary supplements. Food Chem. Toxicol. 2012, 50, 3826-3832. [CrossRef]

13. Viuda-Martos, M.; Ruiz-Navajas, Y.; Fernández-López, J.; Pérez-Álvarez, J.A. Functional properties of honey, propolis, and royal jelly. J. Food Sci. 2008, 73, 117-124. [CrossRef]

14. Sulaiman, G.M.; Sammarrae, K.W.A.; Ad'hiah, A.H.; Zucchetti, M.; Frapolli, R.; Bello, E.; Erba, E.; D'Incalci, M.; Bagnati, R. Chemical characterization of iraqi propolis samples and assessing their antioxidant potentials. Food Chem. Toxicol. 2011, 49, 2415-2421. [CrossRef]

15. Zou, X.Q.; Peng, S.M.; Hu, C.P.; Tan, L.F.; Yuan, Q.; Deng, H.W.; Li, Y.J. Synthesis, characterization and vasculoprotective effects of nitric oxide-donating derivatives of chrysin. Bioorgan. Med. Chem. 2010, 18, 3020-3025. [CrossRef] [PubMed] 
16. Pichichero, E.; Cicconi, R.; Mattei, M.; Canini, A. Chrysin-induced apoptosis is mediated through p38 and Bax activation in B16-F1 and A375 melanoma cells. Int. J. Oncol. 2011, 38, 473-483. [CrossRef]

17. Villar, I.C.; Jiménez, R.; Galisteo, M.; Garcia-Saura, M.F.; Zarzuelo, A.; Duarte, J. Effects of chronic chrysin treatment in spontaneously hypertensive rats. Planta Med. 2002, 68, 847-850. [CrossRef] [PubMed]

18. Rauf, A.; Khan, R.; Raza, M.; Khan, H.; Pervez, S.; De Feo, V.; Maione, F.; Mascolo, N. Suppression of inflammatory response by chrysin, a flavone isolated from Potentilla evestita Th. Wolf. in silico predictive study on its mechanistic effect. Fitoterapia 2015, 103, 129-135. [CrossRef] [PubMed]

19. Kao, Y.C.; Zhou, C.; Sherman, M.; Laughton, C.A.; Chen, S. Molecular basis of the inhibition of human aromatase (estrogen synthetase) by flavone and isoflavone phytoestrogens: A site-directed mutagenesis study. Environ. Health Perspect. 1998, 106, 85-92. [CrossRef] [PubMed]

20. Gambelunghe, C.; Rossi, R.; Sommavilla, M.; Ferranti, C.; Rossi, R.; Ciculi, C.; Gizzi, S.; Micheletti, A.; Rufini, S. Effects of Chrysin on Urinary Testosterone Levels in Human Males. J. Med. Food 2003, 6, 387-390. [CrossRef]

21. Walle, T. Absorption and metabolism of flavonoids. Free Radic. Biol. Med. 2004, 36, 829-837. [CrossRef]

22. Walle, T. Methylation of dietary flavones increases their metabolic stability and chemopreventive effects. Int. J. Mol. Sci. 2009, 10, 5002-5019. [CrossRef]

23. Rodrigues, L.B.; Martins, A.O.B.P.B.; Ribeiro-Filho, J.; Cesário, F.R.A.S.; e Castro, F.F.; de Albuquerque, T.R.; Fernandes, M.N.M.; da Silva, B.A.F.; Quintans Júnior, L.J.; de Sousa Araújo, A.A.; et al. Anti-inflammatory activity of the essential oil obtained from Ocimum basilicum complexed with $\beta$-cyclodextrin $(\beta-C D)$ in mice. Food Chem. Toxicol. 2017, 109, 836-846. [CrossRef]

24. Verri, W.A.; Cunha, T.M.; Parada, C.A.; Poole, S.; Cunha, F.Q.; Ferreira, S.H. Hypernociceptive role of cytokines and chemokines: Targets for analgesic drug development? Pharmacol. Ther. 2006, 112, 116-138. [CrossRef]

25. Medzhitov, R. Origin and physiological roles of inflammation. Nature 2008, 454, 428-435. [CrossRef]

26. Cunha, T.M.; Verri, W.A.; Silva, J.S.; Poole, S.; Cunha, F.Q.; Ferreira, S.H. A cascade of cytokines mediates mechanical inflammatory hypernociception in mice. Proc. Natl. Acad. Sci. USA 2005, 102, 1755-1760. [CrossRef]

27. Rabelo, T.K.; Guimarães, A.G.; Oliveira, M.A.; Gasparotto, J.; Serafini, M.R.; de Souza Araújo, A.A.; Quintans-Júnior, L.J.; Moreira, J.C.F.; Gelain, D.P. Shikimic acid inhibits LPS-induced cellular pro-inflammatory cytokines and attenuates mechanical hyperalgesia in mice. Int. Immunopharmacol. 2016, 39, 97-105. [CrossRef] [PubMed]

28. Quintans, J.S.S.; Antoniolli, Â.R.; Almeida, J.R.G.S.; Santana-Filho, V.J.; Quintans-Júnior, L.J. Natural products evaluated in neuropathic pain models-A systematic review. Basic Clin. Pharmacol. Toxicol. 2014, 114, 442-450. [CrossRef] [PubMed]

29. Hu, L.; Wu, H.; Niu, F.; Yan, C.; Yang, X.; Jia, Y. Design of fenofibrate microemulsion for improved bioavailability. Int. J. Pharm. 2011, 420, 251-255. [CrossRef] [PubMed]

30. Rogerio, A.P.; Dora, C.L.; Andrade, E.L.; Chaves, J.S.; Silva, L.F.C.; Lemos-Senna, E.; Calixto, J.B. Anti-inflammatory effect of quercetin-loaded microemulsion in the airways allergic inflammatory model in mice. Pharmacol. Res. 2010, 61, 288-297. [CrossRef] [PubMed]

31. Li, Q.; Zhai, W.; Jiang, Q.; Huang, R.; Liu, L.; Dai, J.; Gong, W.; Du, S.; Wu, Q. Curcumin-piperine mixtures in self-microemulsifying drug delivery system for ulcerative colitis therapy. Int. J. Pharm. 2015, 490, 22-31. [CrossRef]

32. Premarathne, E.P.N.; Karunaratne, D.N.; Perera, A.D.L.C. Controlled release of diclofenac sodium in glycolipid incorporated micro emulsions. Int. J. Pharm. 2016, 511, 890-898. [CrossRef]

33. Wójcik-Pastuszka, D.; Krzak, J.; Macikowski, B.; Berkowski, R.; Osiński, B.; Musiał, W. Evaluation of the release kinetics of a pharmacologically active substance from model intra-articular implants replacing the cruciate ligaments of the knee. Materials 2019, 12, 1202. [CrossRef]

34. Cavalcanti, A.L.M.; Reis, M.Y.F.A.; Silva, G.C.L.; Ramalho, I.M.M.; Guimarães, G.P.; Silva, J.A.; Saraiva, K.L.A.; Damasceno, B.P.G.L. Microemulsion for topical application of pentoxifylline: In vitro release and in vivo evaluation. Int. J. Pharm. 2016, 506, 351-360. [CrossRef]

35. Naoui, W.; Bolzinger, M.A.; Fenet, B.; Pelletier, J.; Valour, J.P.; Kalfat, R.; Chevalier, Y. Microemulsion microstructure influences the skin delivery of an hydrophilic drug. Pharm. Res. 2011, 28, 1683-1695. [CrossRef]

36. Rastogi, V.; Yadav, P.; Verma, A.; Pandit, J.K. Ex vivo and in vivo evaluation of microemulsion based transdermal delivery of E. coli specific T4 bacteriophage: A rationale approach to treat bacterial infection. Eur. J. Pharm. Sci. 2017, 107, 168-182. [CrossRef]

37. De Oliveira Wanderley Neto, A.; Moura, E.F.; Júnior, H.S.; Dantas, T.N.d.C.; Neto, A.A.D.; Gurgel, A. Preparation and application of self-assembled systems containing dodecylammonium bromide and chloride as corrosion inhibitors of carbon-steel. Colloids Surfaces A Physicochem. Eng. Asp. 2012, 398, 76-83. [CrossRef]

38. Tsai, M.J.; Huang, Y.B.; Fang, J.W.; Fu, Y.S.; Wu, P.C. Preparation and evaluation of submicron-carriers for naringenin topical application. Int. J. Pharm. 2015, 481, 84-90. [CrossRef] [PubMed]

39. Morais, J.M.; Burgess, D.J. In vitro release testing methods for vitamin e nanoemulsions. Int. J. Pharm. 2014, 475, 393-400. [CrossRef] [PubMed]

40. Panapisal, V.; Charoensri, S.; Tantituvanont, A. Formulation of microemulsion systems for dermal delivery of silymarin. AAPS PharmSciTech 2012, 13, 389-399. [CrossRef]

41. Cojocaru, V.; Ranetti, A.E.; Hinescu, L.G.; Ionescu, M.; Cosmescu, C.; Poștoarcă, A.G.; Cinteză, L.O. Formulation and evaluation of in vitro release kinetics of Na3CaDTPA decorporation agent embedded in microemulsion-based gel formulation for topical delivery. Farmacia 2015, 63, 656-664. 
42. Pundir, S.; Badola, A.; Sharma, D. Sustained Release Matrix Technology and Recent Advance in Matrix Drug Delivery System: A Review. Int. J. Drug Res. Technol. 2013, 3, 12-20.

43. García, M.D.; Fernández, M.A.; Alvarez, A.; Saenz, M.T. Antinociceptive and anti-inflammatory effect of the aqueous extract from leaves of Pimenta racemosa var. ozua (Mirtaceae). J. Ethnopharmacol. 2004, 91, 69-73. [CrossRef]

44. Dutra, R.C.; Simão Da Silva, K.A.B.; Bento, A.F.; Marcon, R.; Paszcuk, A.F.; Meotti, F.C.; Pianowski, L.F.; Calixto, J.B. Euphol, a tetracyclic triterpene produces antinociceptive effects in inflammatory and neuropathic pain: The involvement of cannabinoid system. Neuropharmacology 2012, 63, 593-605. [CrossRef] [PubMed]

45. Wang, Y.; Chen, P.; Tang, C.; Wang, Y.; Li, Y.; Zhang, H. Antinociceptive and anti-inflammatory activities of extract and two isolated flavonoids of Carthamus tinctorius L. J. Ethnopharmacol. 2014, 151, 944-950. [CrossRef]

46. Habib, M.; Waheed, I. Evaluation of anti-nociceptive, anti-inflammatory and antipyretic activities of Artemisia scoparia hydromethanolic extract. J. Ethnopharmacol. 2013, 145, 18-24. [CrossRef]

47. Woo, K.J.; Jeong, Y.J.; Inoue, H.; Park, J.W.; Kwon, T.K. Chrysin suppresses lipopolysaccharide-induced cyclooxygenase-2 expression through the inhibition of nuclear factor for IL-6 (NF-IL6) DNA-binding activity. Fed. Eur. Biochem. Soc. 2005, 579, 705-711. [CrossRef]

48. He, X.L.; Wang, Y.H.; Bi, M.G.; Du, G.H. Chrysin improves cognitive deficits and brain damage induced by chronic cerebral hypoperfusion in rats. Eur. J. Pharmacol. 2012, 680, 41-48. [CrossRef]

49. Jiang, Y.; Gong, F.L.; Zhao, G.B.; Li, J. Chrysin Suppressed Inflammatory Responses and the Inducible Nitric Oxide Synthase Pathway after Spinal Cord Injury in Rats. Int. J. Mol. Sci. 2014, 15, 12270-12279. [CrossRef]

50. Khan, J.; Noboru, N.; Young, A.; Thomas, D. Pro and anti-inflammatory cytokine levels (TNF- $\alpha$, IL-1 $\beta$, IL-6 and IL-10) in rat model of neuroma. Pathophysiology 2017, 24, 155-159. [CrossRef]

51. Likhitpanichkul, M.; Torre, O.M.; Gruen, J.; Walter, B.A.; Hecht, A.C.; Iatridis, J.C. Do mechanical strain and TNF- $\alpha$ interact to amplify pro-inflammatory cytokine production in human annulus fibrosus cells? J. Biomech. 2016, 49, 1214-1220. [CrossRef] [PubMed]

52. Ujhelyi, Z.; Kalantari, A.; Vecsernyés, M.; Róka, E.; Fenyvesi, F.; Póka, R.; Kozma, B.; Bácskay, I. The enhanced inhibitory effect of different antitumor agents in self-microemulsifying drug delivery systems on human cervical cancer HeLa cells. Molecules 2015, 20, 13226-13239. [CrossRef]

53. Opal, S.M.; DePalo, V.A. Anti-inflammatory cytokines. Chest 2000, 117, 1162-1172. [CrossRef] [PubMed] 